$15^{\text {th }}$ International Conference on

AEROSPACE SCIENCES \& AVIATION TECHNOLOGY,

$\boldsymbol{A S A T}$ - 15 - May 28 - 30, 2013, Email: asat@mtc.edu.eg,

Military Technical College, Kobry Elkobbah, Cairo, Egypt,

Tel: +(202) 24025292-24036138, Fax: +(202) 22621908

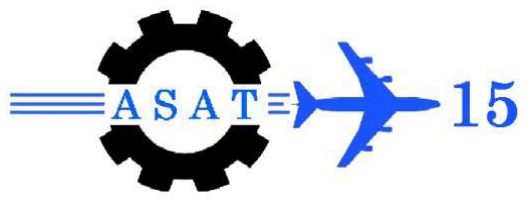

\title{
Binary Brayton Cycle with Isothermal Concept
}

\section{R. M. Abd El-Maksoud*}

\begin{abstract}
The literature introduced binary Brayton cycle and the isothermal concept as two promising methods used to enhance the performance of the gas turbine. Consequently, this work presents a cycle based on the blending of the two methods. This cycle is composed of gas turbine topping cycle with isothermal combustion and air turbine bottoming cycle with isothermal heating. Different parameters affecting the cycle performance have been studied. Simulations demonstrate that the present cycle achieves drastic enhancement in performance. The cycle merits justify its potential utilization for future power generation.
\end{abstract}

Keywords: Isothermal combustion, Isothermal heating, Binary cycle, Brayton cycle, Gas turbine.

\section{Nomenclature}

$\mathrm{C}_{\mathrm{p}} \quad$ Specific heat at constant pressure $\left(\mathrm{kJ} / \mathrm{kg}^{\circ} \mathrm{K}\right)$

M Mach number

Q isobar Specific isobaric input heat to the cycle $(\mathrm{kJ} / \mathrm{kg})$

$\mathrm{Q}_{\text {isoth }}$ Specific isothermal input heat to the cycle $(\mathrm{kJ} / \mathrm{kg})$

$\mathrm{Q}_{\text {total }} \quad$ Specific total input heat to the cycle $(\mathrm{kJ} / \mathrm{kg})$

$\mathrm{R}_{\mathrm{t}} \quad$ Isothermal unit expansion ratio

$\mathrm{T} \quad$ Temperature $\left({ }^{\mathrm{o}} \mathrm{K}\right)$

$\mathrm{T}_{\mathrm{r}} \quad$ Temperature ratio, $\mathrm{T} 3 / \mathrm{T} 1$

$\mathrm{w}_{\mathrm{c}} \quad$ Specific work of the topping cycle compressor $(\mathrm{kJ} / \mathrm{kg})$

$\mathrm{W}_{\text {net }} \quad$ Net specific work of the topping cycle $(\mathrm{kJ} / \mathrm{kg})$

$\mathrm{w}_{\mathrm{t}} \quad$ Specific work of the topping cycle turbine $(\mathrm{kJ} / \mathrm{kg})$

\section{Symbols}

$\varepsilon \quad$ Regenerative heater effectiveness

$\gamma \quad$ Specific heat ratio

$\eta \quad$ Isentropic efficiency

$\pi \quad$ Pressure ratio of the topping cycle

\section{Subscripts}

1 Compressor inlet condition

2 Compressor outlet condition

3 Combustor (topping cycle) outlet or regenerative (bottoming cycle) outlet condition

$4 \quad$ Inlet to turbine

5 Turbine outlet condition

Assistant professor, Faculty of Eng., Mataria, Helwan University, Cairo, Egypt; brainandspirit@yahoo.com 
$6 \quad$ Regenerative heater inlet condition of topping cycle flow

7 Regenerative heater outlet condition of topping cycle flow

b Bottoming cycle, without this subscript means topping cycle

c Compressor

s Isentropic condition

$\mathrm{t}$ Turbine

\section{Introduction}

Many investigations have been performed in order to increase gas turbine output power and/or efficiency in all possible ways. Maximum cycle temperature is achieved using blade cooling [1] or using different blade alloys [2]. In order to increase the cycle average maximum temperature, reheating has been investigated by [3]. Other studies have been focused to minimize the cycle sink temperature by operating in combined cycle [4-6]. In comparison to the conventional combined cycle; binary Brayton cycle does not require bulky steam equipment (boiler, steam turbine, condenser), and water processing unit. Several researchers [7-14] investigated the binary system and showed the feasibility of this configuration. It is mentioned from [11] that, for the Allison $571 \mathrm{~K}$ topping gas turbine, introduction of the air bottoming cycle with two inter-coolers led to an increase in power from 5.9 to $7.5 \mathrm{MW}$ and in efficiency from $33.9 \%$ to $43.2 \%$. The recent trend is to utilize binary Brayton cycle where the air bottoming cycle replaces Rankine unit. This reduces the cost of hardware installations as well as it could achieve a thermal efficiency of about 49\%, which does not deteriorate at part load as happens with the basic gas turbine engine [10].

Utilizing isothermal heating (sometimes referring to the convergent combustion chamber [15]) is useful to increase of cycle work and efficiency of the gas turbine. Isothermal heating is a process in-between two processes that are; isobaric heating and isentropic expansion. Isobaric heating is performed in a constant area duct while isentropic expansion process could be accomplished in a nozzle. Therefore, the isothermal heating process could be achieved when certain specified amount of heat is transferred to a gas while expanding in a nozzle at a constant temperature. This process is achieved in the form of increasing of the flow kinetic energy while suffering from a slight pressure drop, [16]. This recent known concept is used due to the limitation of maximum temperature entering the gas-turbine [16, 17]. This will avoid blade inter-cooling and their bulk problems. The researchers [15-21] illustrated that the application of the isothermal heating process in the Brayton cycle yields to a significant increase in the cycle thermal efficiency and output work.

The aim of the present work is to present a promising cycle having a high-output power and efficiency. Consequently, the author introduces a cycle based on the blending between binary Brayton cycle and the isothermal concept. The cycle presented herein is composed of gas turbine topping cycle with isothermal combustion and air turbine bottoming cycle with isothermal heating. The current investigation represents a new approach that is not found in the literature. Different parameters affecting the performance of the cycle are investigated. The results have been derived numerically and summarized by figures.

\section{System Layout}

The schematic layout of the present cycle and its $\mathrm{T}-\mathrm{s}$ processes are shown in Figs. 1 and 2, respectively. This cycle is composed of topping and bottoming cycles. The basic components of the topping cycle are; compressor, combustion chamber, isothermal combustion unit and turbine. For the bottoming cycle, the main components are; compressor, regenerative heater, 
isothermal regenerative heating unit and turbine. The flow enters the compressor at state 1 and is compressed to state 2 or is compressed isentropically to state $2 \mathrm{~s}$. Here, s denotes the isentropic condition at any point on the figure. The flow enters the combustion chamber gases and leaves it at state 3 . Further heating is accomplished in the isothermal combustion unit from state 3 to state 4 where such unit may be an integral or extended part of the combustion chamber. Isothermal combustion may be achieved by using some fuel injected from injectors placed longitudinally in the isothermal combustion unit. The gas enters the turbine at state 4 has a lower pressure than at state 3, where the kinetic energy of the gas has increased due to the nature of the isothermal heating unit. The gas expands in the turbine till state 5 . The exhaust gases enter the isothermal regenerative heating unit of the bottoming cycle where it is cooled at a constant pressure to state 6 . Finally, the flow enters the conventional regenerative heater of the bottoming cycle and is cooled to state 7 at a constant pressure. For the bottoming cycle, air at state $1 \mathrm{~b}$ is compressed by bottoming cycle compressor to state $2 \mathrm{~b}$. The air is heated isobarically in regenerative heater to state $3 b$ then is further heated isothermally in isothermal regenerative heating unit to state $4 \mathrm{~b}$. Finally, air expands in the air turbine to state $5 b$.

The present cycle proposed by the author is justified by improving cycle performance, although the cycle area is increased. This is achieved by the increase in the kinetic energy of the gasses admitted to the turbine. Using the isothermal concept with Brayton cycle is a potential solution for the limitation of maximum temperature. However, this leads to raise the exhaust temperature. In this case, there is a need of using bottoming cycle, otherwise; the waste heat transferred to the surrounding is very high. On the other side, using the binary cycle without the isothermal concept is restricted by maximum temperature of topping and bottoming cycles. Moreover, for the bottoming cycle, the heat transfer to air is limited by the effectiveness of the regenerative heater and the temperature difference between the exhaust gases and air.

In order to operate this cycle at its highest efficiency, especially for small-scale power generation; the author proposed that each of the two compressors and the two turbines operates at its design speed. This could be achieved by using split shaft layout as demonstrated in the findings of [22]. Fig. 3 shows this proposed layout where a portion of the electric power is supplied from each generator driven by the two turbines to the electric motors driving the two compressors. The other portion of power supplies the load. It is notable to mention that some types of electric motors and generators are available having compact features with high power to weight ratio making the feasibility of this system possible.

\section{System Analysis}

For the topping cycle, referring to Figs. 1 and 2, the relation of flow temperature at compressor inlet, $T_{1}$, and the actual temperature at the outlet, $T_{2}$, could be written as:

$$
T_{2} / T_{1}=\left(\pi^{\frac{\gamma-1}{\gamma}}-1\right) / \eta_{c}+1
$$

where, $\gamma$ is the specific heat ratio, $\eta$ is the efficiency, $\pi$ is the pressure ratio and the subscript $c$ is compressor. Whereas, the subscripts having numbers can be determined from Figs. 1 and 2. The specific heat quantity of the isobar process, $\mathrm{q}_{\text {isobar }}$, can be expressed as: 


$$
q_{\text {isobar }}=C_{p} T_{3}\left(1-T_{2} / T_{3}\right)=C_{p} T_{3}\left(1-\left(\pi^{\frac{\gamma-1}{\gamma}}+\eta_{c}-1\right) /\left(\eta_{c} T_{r}\right)\right)
$$

where $C_{p}$ is the specific heat at constant pressure, and $T_{r}$ is the temperature ratio $T_{3} / T_{1}$. For the isothermal combustion unit, the specific heat quantity for the isothermal process, $\mathrm{q}_{\text {isoth }}$, is determined by the injected fuel to the mainstream. This quantity of heat results in increasing of the kinetic energy of the flow passing through the isothermal unit at constant temperature. Since the fuel to air ratio is very small and can be neglected, $\mathrm{q}_{\text {isoth }}$ is determined by the formula presented in the findings of [16] that can be written as:

$q_{\text {isoth }}=0.5 C_{p} T_{3}(\gamma-1)\left(M_{4}^{2}-M_{3}^{2}\right)$

where $\mathrm{M}$ is Mach number. Heat for isothermal process is indicated by the increase of Mach number. Using Eqs. (2 and 3), the specific heat given to the topping cycle is:

$$
q_{\text {total }}=C_{p} T_{3}\left(1-\left(\pi^{\frac{\gamma-1}{\gamma}}+\eta_{c}-1\right) /\left(\eta_{c} T_{r}\right)+0.5(\gamma-1)\left(M_{4}^{2}-M_{3}^{2}\right)\right)
$$

Neglecting the gas velocity at the compressor entry, the specific work of the topping cycle compressor, $\mathrm{w}_{\mathrm{c}}$, can be written as:

$w_{c}=C_{p} T_{1}\left(T_{2 s} / T_{1}-1\right) / \eta_{c}+0.5 C_{p} T_{2}(\gamma-1) M_{2}^{2}$

where the subscript $\mathrm{s}$ is the isentropic condition and the subscript $\mathrm{t}$ is the turbine. Neglecting the gas velocity at the turbine exit, the specific work of the topping cycle turbine, $\mathrm{w}_{t}$, can be written as:

$$
w_{t}=\eta_{t} C_{p}\left(T_{3}-T_{5}\right)+0.5 C_{p} T_{3}(\gamma-1) M_{4}^{2}
$$

Consequently, the net specific work of the topping cycle is expressed as:

$$
w_{n e t}=C_{p} T_{3}\left(\eta_{t}\left(1-1 /\left(r_{t} \pi\right)^{\frac{\gamma-1}{\gamma}}\right)+0.5(\gamma-1)\left(M_{4}^{2}-T_{2} M_{2}^{2} / T_{3}\right)-T_{1}\left(\pi^{\frac{\gamma-1}{\gamma}}-1\right) /\left(T_{3} \eta_{c}\right)\right)
$$

where $r_{t}$ is the isothermal unit expansion ratio, and $\eta_{t}$ is the turbine efficiency. From Eqs. (4 and 7), the topping cycle efficiency could be assigned. Similarly to the above analyses, the equations that specify bottom cycle performance could be deduced. However, from the energy balance of the isothermal heating unit, $\mathrm{T}_{6}$ could be determined as:

$T_{6}=T_{5}-0.5 T_{3 b}(\gamma-1)\left(M_{4}^{2}-M_{3}^{2}\right)$

where the subscript $b$ denotes the conditions of the bottoming cycle. In the above equation, $C_{p}$ of air and that of the gas are considered equal. The effectiveness of the regenerative heater, $\varepsilon$, that is used to determine point $3 \mathrm{~b}$ can be expressed as:

$\varepsilon=\left(T_{3 b}-T_{2 b}\right) /\left(T_{6}-T_{2 b}\right)$

Consequently, the whole conditions of the bottoming cycle could be specified. The work and efficiency of the present cycle could then be assigned.

\section{Results and Discussion}

The flow mass of the topping and that of bottoming cycle are selected to have the same values. The results are performed based on varying the pressure ratio of the topping cycle from 8 to 16 and varying its maximum temperature $\left(\mathrm{T}_{3}=\mathrm{T}_{4}\right)$ from $1200^{\circ} \mathrm{K}$ to $1600^{\circ} \mathrm{K}$.

Figure 4 demonstrates the relation between work and efficiency of the simple cycle, the binary cycle, and the simple cycle with the isothermal combustion. The two proposed enhancement methods achieve sensible improvement in cycle efficiency and work. For a qualitative comparison, the isothermal combustion shows more improvement than the binary 
cycle. The general feature of the results is that the maximum cycle temperature and the topping cycle pressure ratio $(\pi)$ have a sensible influence on both cycle work and efficiency.

Figure 5 shows the influence of topping and bottoming cycle pressure ratios $\left(\pi\right.$ and $\left.\pi_{b}\right)$ on the performance of the bottoming cycle and the binary cycle. The maximum cycle temperature is selected to be $1600^{\circ} \mathrm{K}$. Higher valves of $\pi$ and $\pi_{\mathrm{b}}$ cycle result in enhancing the work and efficiency of the bottoming cycle and affect sensibly the performance of the binary cycle.

Figure 6 and the following figures demonstrate the performance of the present cycle that is specified by the combining of binary cycle and isothermal concept. Figure 6 demonstrates the effect of the isothermal expansion ratio of the topping cycle $\left(r_{t}\right)$ on the present cycle, its bottoming cycle and its topping cycle. Here, $\mathrm{M}_{4}, \mathrm{~T}_{3}, \pi, \pi_{\mathrm{b}}$ and isothermal expansion ratio of the bottoming cycle $\left(\mathrm{r}_{\mathrm{tb}}\right)$ are assigned to be equal to $0.6,1200^{\circ} \mathrm{K}, 8,3$ and 0.9 , respectively. Increase of $r_{t}$ leads to elevate the work and efficiency of the present cycle, the work of its topping cycle and reduces the work of its bottoming cycle and $\mathrm{T}_{5}$. These results give a good reason for taking the value of $r_{t}$ to be equal to 0.9 as in [16].

Figure 7 illustrates the effect of the isothermal heat quantity on the present cycle performance. Increase of the isothermal heat quantity is indicated by the raising the Mach number at the isothermal unit outlet. Here, the cycle is examined when the two isothermal units of the topping and bottoming cycles having the same Mach number at exit, $\mathrm{M}_{4}=\mathrm{M}_{4 \mathrm{~b}}$, that is equal to 0.6, 0.7 and 0.8. The present cycle achieves drastic improvement with the increase of Mach number.

Figure 8 summarizes the different modifications applied to Brayton cycle. These modifications are the binary cycle, the simple cycle with the isothermal concept at $\mathrm{M}_{4}=0.6$, and the binary cycle with isothermal processes (the present cycle) at $\mathrm{M}_{4}=\mathrm{M}_{4 \mathrm{~b}}=0.8$. As one may notice that utilizing the two methods separately attains sensible cycle performance improvement while utilizing both methods together achieves drastic enhancement. The present cycle shows slightly lower efficiency than the current commercially available combined cycle. This is because of not using reheat in the present cycle, and many modifications may be introduced. Consequently, the present cycle may be considered as a promising power generation cycle with low thermal emissions and environmental impact since the average sink temperature is reduced.

\section{Conclusions}

From the study, the following conclusions may be drawn:

1. This paper represents a cycle based on the blending of the binary Brayton cycle and isothermal concept. This cycle is composed of gas turbine topping cycle with isothermal combustion and air turbine bottoming cycle with isothermal heating.

2. Binary cycle and Brayton cycle operating with the isothermal concept achieve sensible cycle performance improvement compared with the Brayton cycle.

3. The present cycle has drastic improvement in performance that justifies its potential utilization for future power generation.

4. Different parameters such as; topping and bottoming cycle pressure ratios, maximum cycle temperature, and isothermal unit expansion ratio have a sensible influence on the present cycle performance.

5. Significant improvement of the present cycle is established with the increase of Mach number at the exit of the two isothermal units. 


\section{References}

[1] Gao, Z., Narzary, D.P., and Han, J., "Film cooling on a gas turbine blade pressure side or suction side with axial shaped holes", International Journal of Heat and Mass Transfer, 2008, vol. 51, pp. 2139-2152.

[2] Sujata, M., Madan, M., Raghavendra, K., Venkataswamy, M.A., and Bhaumik, S.K., "Identification of failure mechanisms in nickel base superalloy turbine blades through microstructural study", Engineering Failure Analysis, 2010, vol. 17, pp. 1436-1446.

[3] Khaliq, A., and Kaushik, S.C., "Thermodynamic performance evaluation of combustion gas turbine cogeneration system with reheat", Applied Thermal Engineering, 2004, vol. 24, pp. 1785-1795.

[4] Boonnasa, S., and Namprakai, P., "Sensitivity analysis for the capacity improvement of a combined cycle power plant (100-600 MW)". Applied Thermal Engineering, 2008, vol. 28, pp. 1865-1874.

[5] Srinivas, T., Gupta, A.V.S.S.K.S, and Reddy, B.V., "Sensitivity analysis of STIG based combined cycle with dual pressure HRSG", International Journal of Thermal Sciences, 2008, vol. 47 , pp. 1226-1234.

[6] Weston, K.C., "Dual gas turbine combined cycles", Proceedings of the 28th Intersociety Energy Conversion Engineering Conference, Boston, 1993, vol. 1, pp. 955-958.

[7] Alderson, E.D., "Air bottoming cycle for coal gasification plant", United States Patent No 4785621 Nov. 1988.

[8] Bolland, O., Førde, M., and Hande, B., "Air bottoming cycle. Use of gas turbine waste heat for power generation", ASME Paper 95-CTP-50.

[9] Hirs, G.G., Wagener, M.T.P.A., and Korobitsyn, M.A., "Performance analysis of the dual gas turbine combined cycle", Thermodynamics and the Design, Analysis, and Improvement of Energy Systems, ASME Publications, New York, 1995, vol. 35, pp. 255-259.

[10] Najjar, Y.H., and Zaamout, M.S., "Performance analysis of gas turbine air-bottoming combined system", Energy Conversion and Management, 1996, vol. 37, pp. 399-403.

[11] Korobitsyn, M.A., "New and advanced energy conversion technologies-analysis of cogeneration, combined and integrated cycles", $\mathrm{PhD}$. Thesis, University of Twente; 1998.

[12] Korobitsyn, M.A., "Industrial applications of the air bottoming cycle", Energy Conversion and Management, 2002, vol. 43, pp. 1311-1322.

[13] Johnson, P.K., and Mason, L.S., "Performance and operational characteristics for a dual Brayton space power system with common gas inventory", Fourth International Energy Conversion Engineering Conference and Exhibit, San Diego, California June, 2006, pp. 26-29.

[14] Ghazikhani, M., Passandideh-Fard, M., and Mousavi, M., "Two new high-performance cycles for gas turbine with air bottoming”, Energy, 2011, vol. 36, pp. 294-304

[15] Erbay, L.B, Göktun, S., and Yavuz, H., "Optimal design of the regenerative gas turbine engine with isothermal heat addition", Applied Energy, 2001, vol. 68, pp. 249-264.

[16] Göktun, S., and Yavuz, H., "Thermal efficiency of a regenerative Brayton cycle with isothermal heat addition”, Energy Conversion and Management, 1999, vol. 40, pp. 1259-1266.

[17] Vecchiarelli, J., Kawall, J.G., and Wallace, J.S., "Analysis of a concept for increasing the efficiency of a Brayton cycle via isothermal heat addition", International Journal of Energy Research, 1997, vol. 21, pp. 113-127.

[18] Tyagi, S.K., "Application of finite time thermodynamics and second law evaluation of thermal energy conversion systems", PhD Thesis, C.C.S. University, Meerut (UP), India; 2000. 
[19] Tyagi, S.K., Kaushik, S.C., and Tyagi, B.K., "Thermodynamic analysis of a regenerative Brayton cycle with isothermal heat addition", NREC, IIT, Bombay, India 2000, Nov. 30-Dec. 2, 2000, pp. 419-424.

[20] Kaushik, S.C., Tyagi, S.K., and Singhal, M.K., "Parametric study of an irreversible regenerative Brayton cycle with isothermal heat addition", Energy Conversion and Management, 2003, vol. 44, pp. 2013-2025.

[21] Chiu, Y., "A performance study of a super-cruise engine with isothermal combustion inside the turbine", Ph.D., Virginia Uni., Blacksburg, Mechanical Engineering, 2004.

[22] Bayomi, N.N., and Abd El-Maksoud, R.M., "Two operating modes for turbocharger system”, Energy Conversion and Management, 2012, vol. 58, pp. 59-65. 


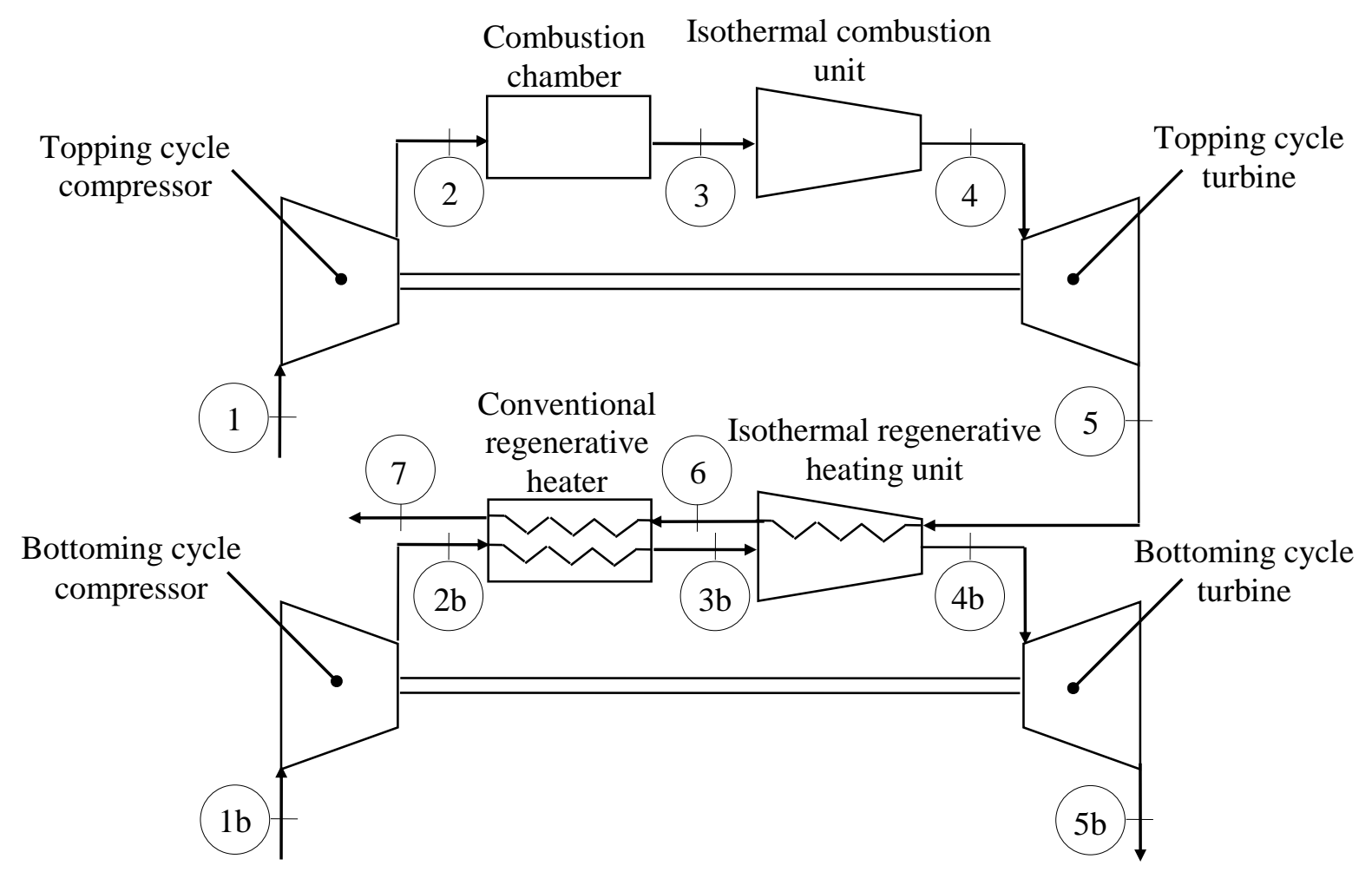

Fig. 1 Layout of the present cycle.

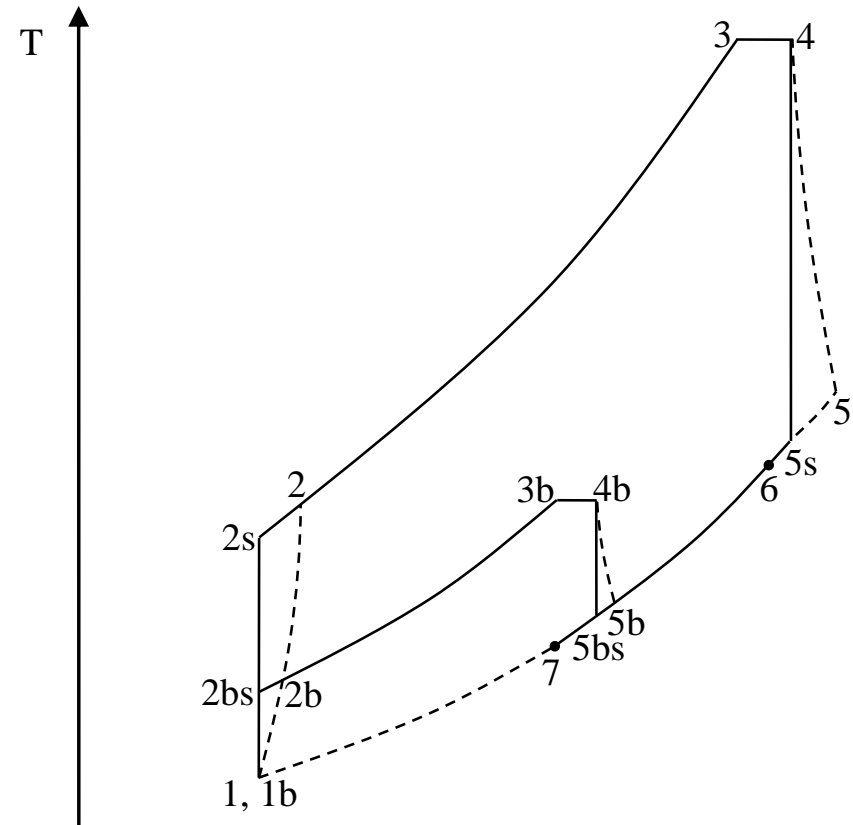

Fig. 2 T-s diagram of the present cycle. 


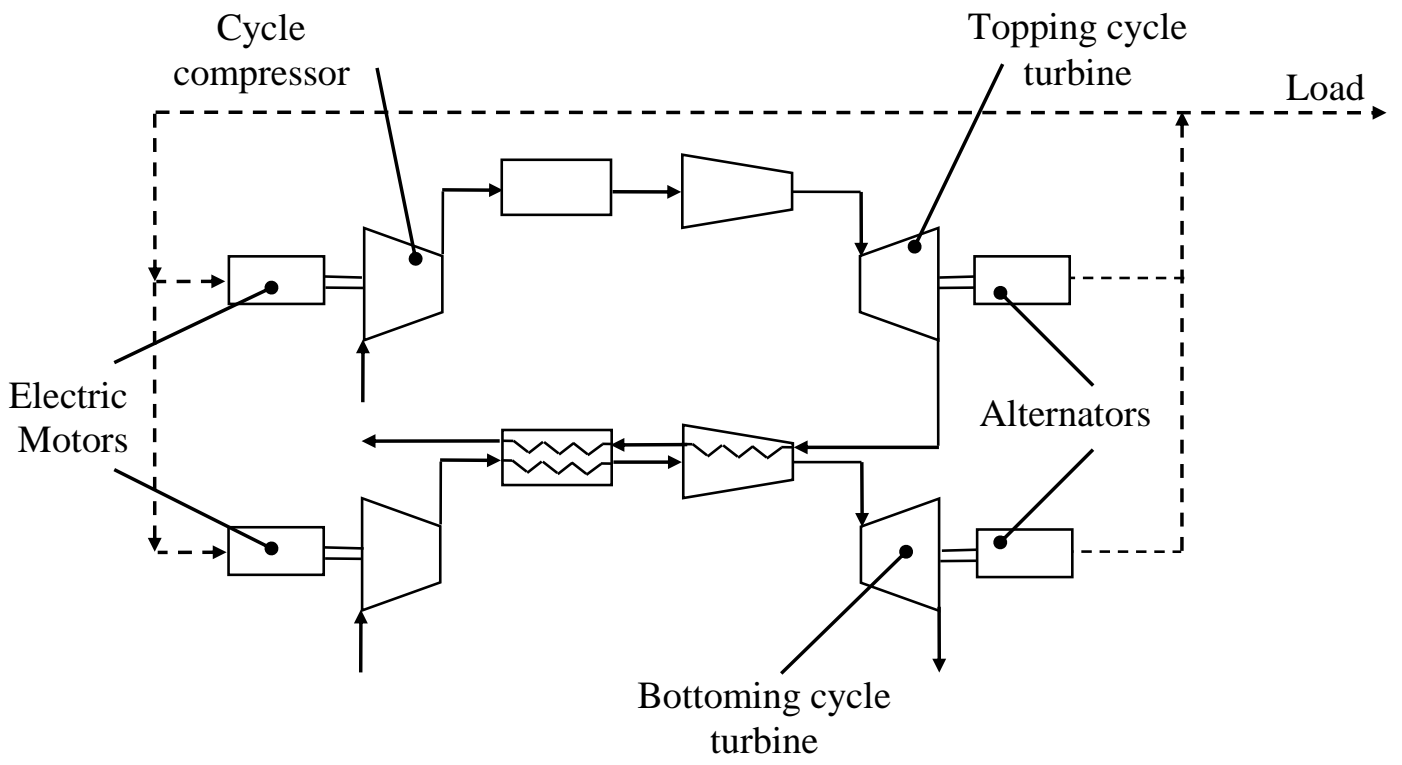

Fig. 3 The present cycle operating with split shaft configuration.

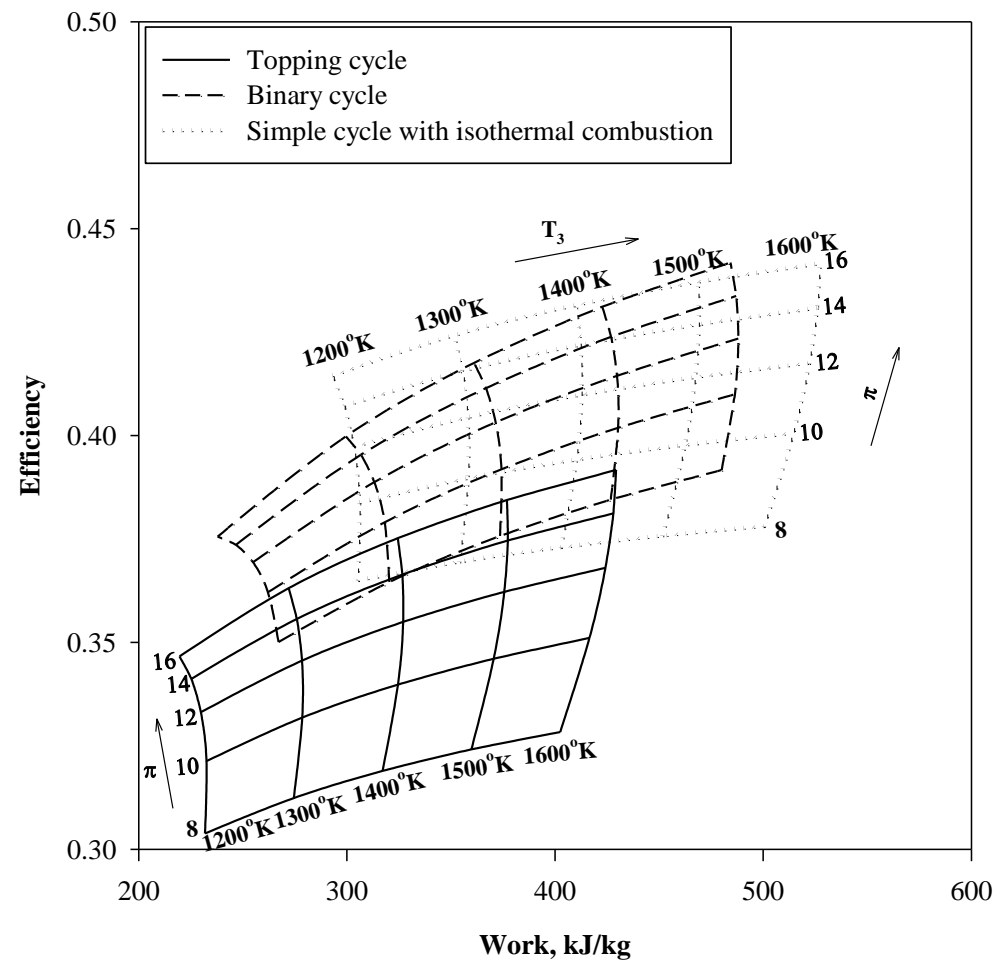

Fig. 4 Performance map of the simple cycle, binary cycle, and simple cycle with the isothermal concept. 


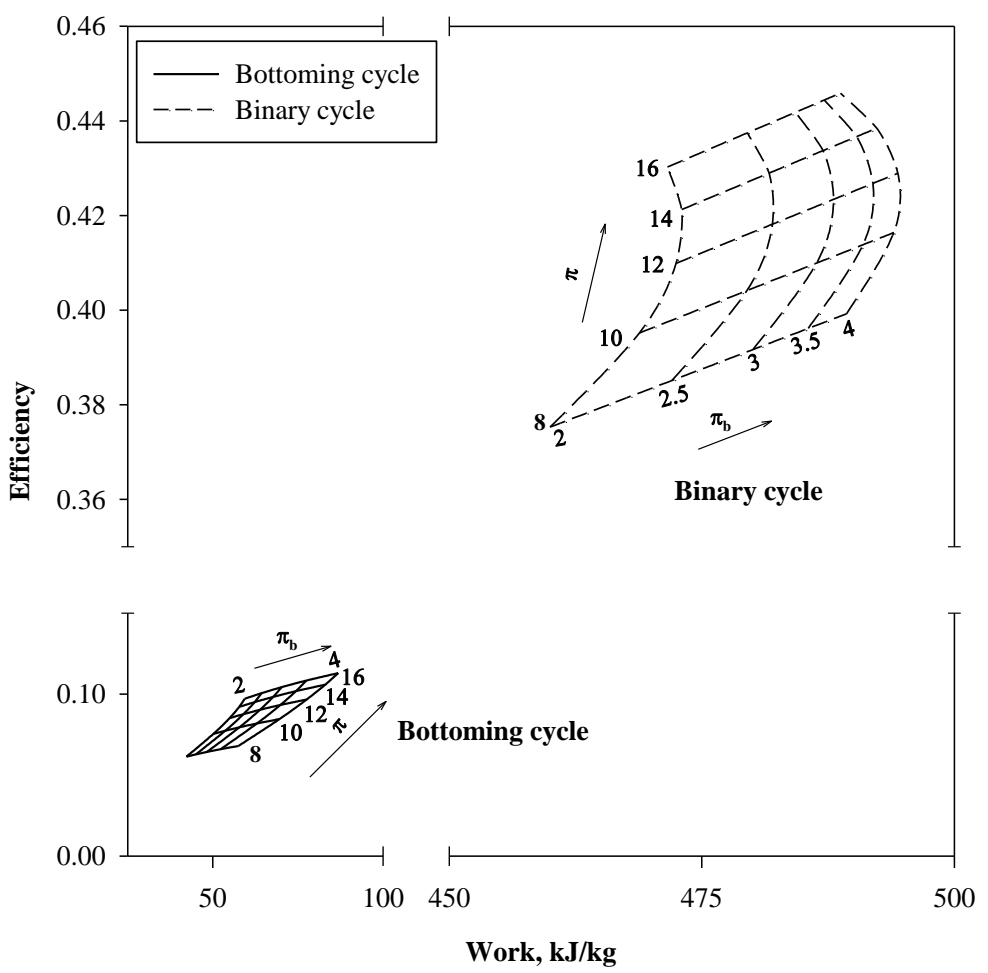

Fig. 5 Effect of $\pi$ and $\pi_{b}$ on the bottoming cycle and the binary cycle.

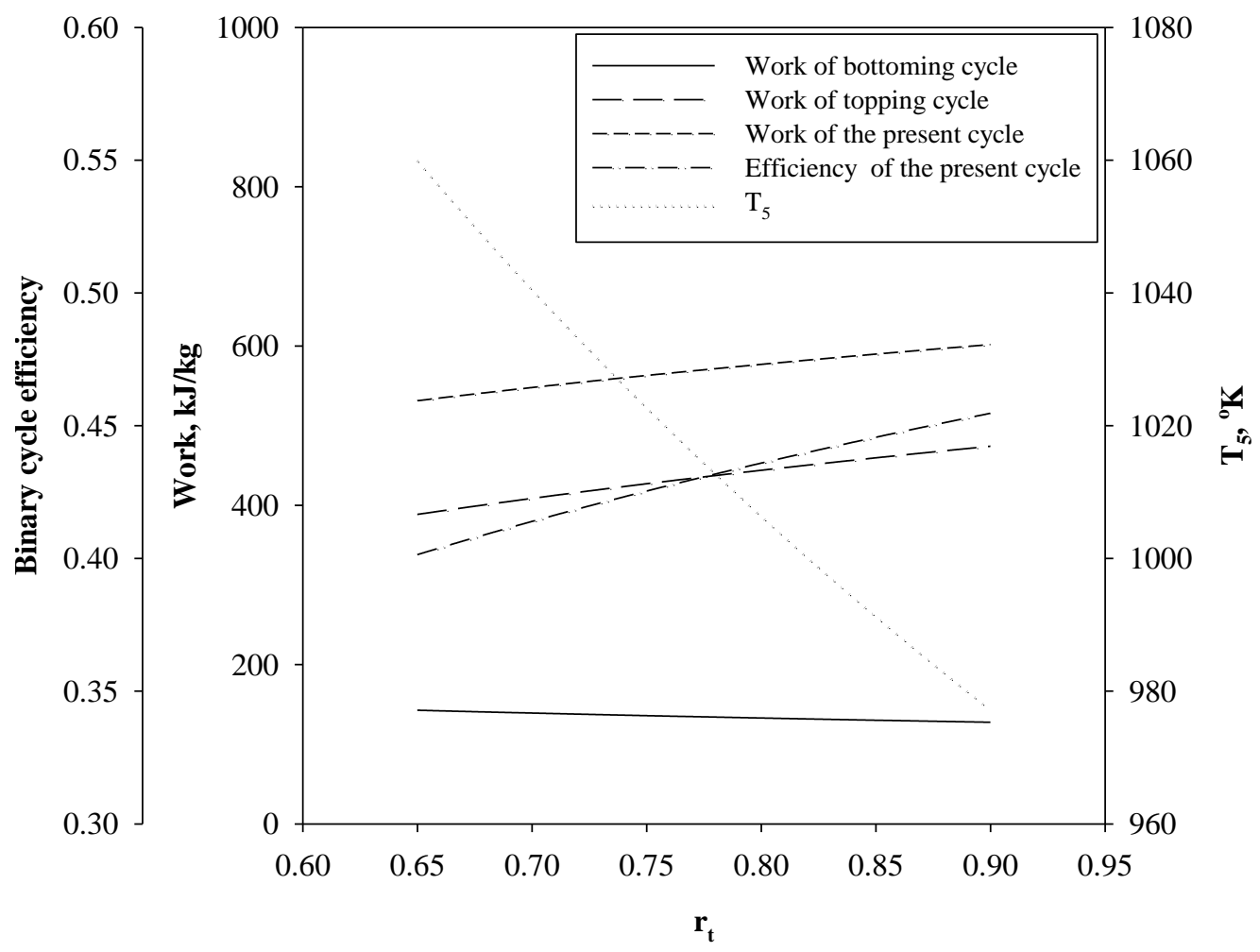

Fig. 6 The influence of $r_{t}$ on the present cycle, its bottoming cycle and its topping cycle. 


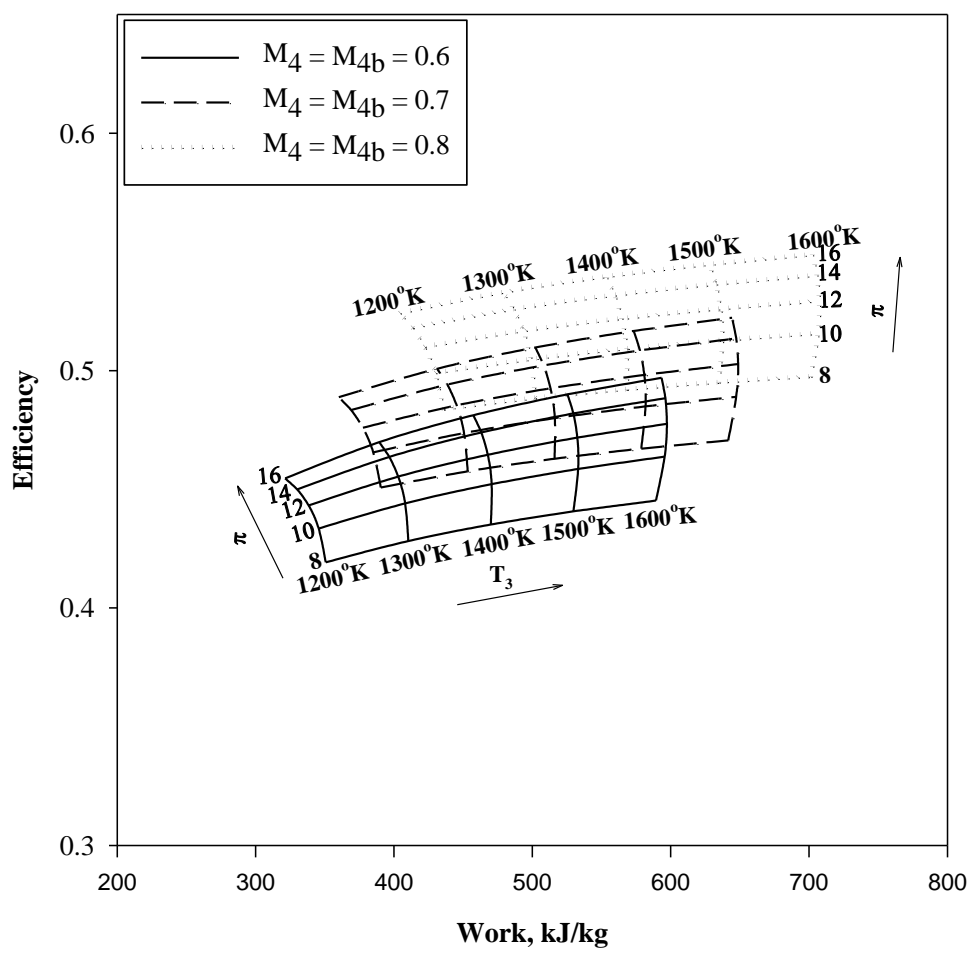

Fig. 7 The effect of the isothermal heat quantity on the present cycle performance.

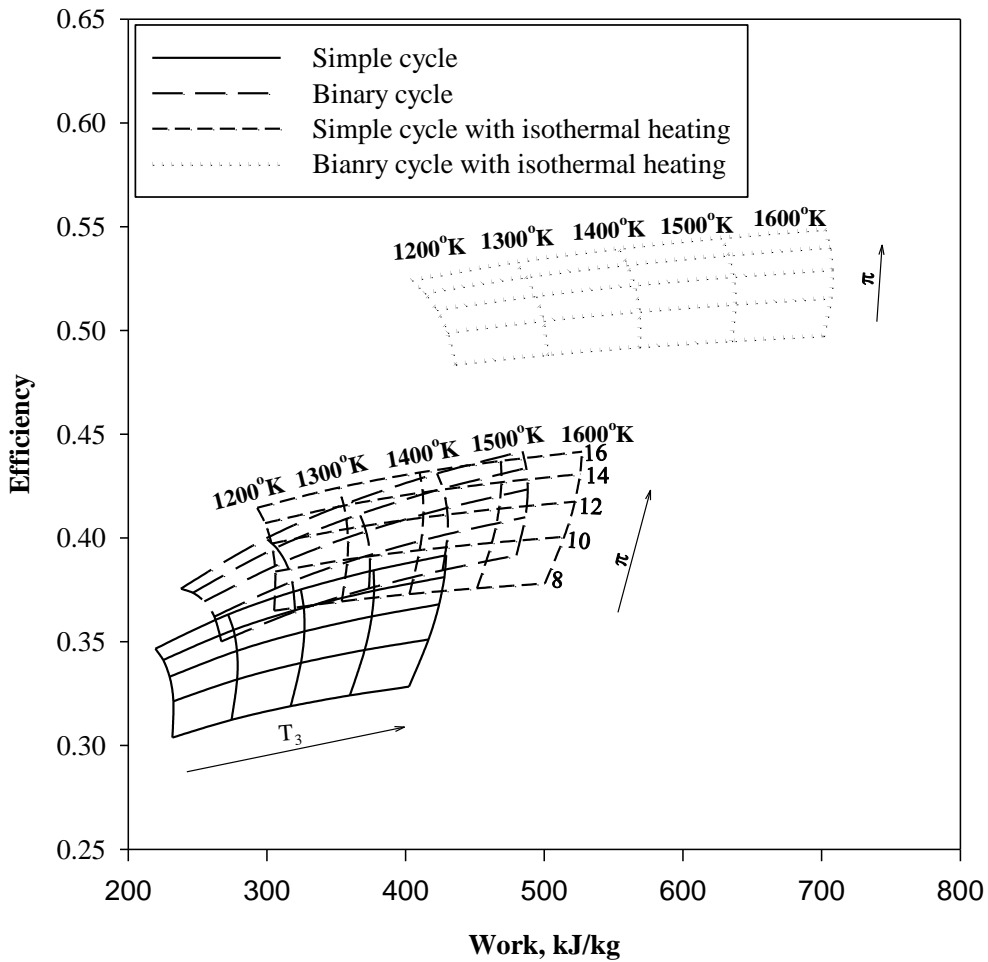

Fig. 8 The different modifications applied to the simple Brayton cycle. 